\title{
Co-evolution of Supply Chain Strategies and Technologies
}

\author{
Mohdzaher B. Mohdzain ${ }^{1}$, Andrew D. White ${ }^{2}$ and John M. Ward ${ }^{3}$ \\ ${ }^{1}$ Universiti Kebangsaan Malaysia, Selangor, Malaysia \\ ${ }^{2}$ Oxford University, United Kingdom \\ ${ }^{3}$ Cranfield University, United Kingdom
}

\begin{abstract}
This paper proposes a framework that seeks to denote the relationship and promote a better alignment between the evolution of supply chain strategies and technologies. In the supply chain strategy, the focal shift in strategy has been from lean supply chain to a combination of lean and agile supply chain, whereas in supply chain technology the focal shift has been from individual and dyadic to global, inter-organisational systems. Examples of these systems include Vendor-Managed Inventory and Web-based Electronic Data Interchange. These systems increase visibility of information within the supply network and require a high level of trust between the trading partners. Since most inter-organisational systems are developed by IT vendors, the concepts of visibility and trust must be understood by these vendors and translated into the systems they develop. The proposed framework emphasizes the focus on fit and alignment between progress in supply chain strategies and IT strategies that would potentially enable agility as well as trust and visibility within the supply network.
\end{abstract}

Keywords: Supply Chain Management, Information Systems, Information Technology

\section{Introduction}

This paper discusses the co-evolution of supply chain strategies and technologies and proposes a framework that seeks to denote the relationship and promote a better alignment between the evolution of supply chain strategies and technologies. This paper is divided into several sections that include the evolution of supply chain strategies, the evolution of supply chain technologies and an analysis of the literature on the co-evolution of both supply chain strategies and technologies that leads to the development of the proposed framework.

\section{Evolution of Supply Chain Strategies}

The emergence of the concept of supply chain management encompasses a number of factors present in the evolving nature of how organisations co-operate and compete. This includes the use of virtual teams (Bal et al, 1999), sharing risks and rewards (Cooper and Ellram, 1993), integration of business processes (Christopher, 2000), improved information sharing (Morash, 2001) and developing long-term relationships with key suppliers (Schonsleben, 2000). The concept of supply chain management does not limit itself to the dyad, but positions the dyad as a component within a larger system - that of multiple dyads that work together in the form of supply networks. Managing a single organisation within such networks requires a number of competencies to be developed by managers that include the development of a supply chain orientation and philosophy amongst managers (Mentzer et al, 2001); a vision for the 
supply chain that is underpinned with key processes (Lambert, et al 1998); a realization that competition can be between supply chains as well as individual organisations (Christopher, 2000); and the role of information systems that facilitate multi-tier integration (Garcia-Dastugue and Lambert, 2003).

Systems and processes within organisations are under increasing pressure to be more flexible and agile, in order to maintain and increase levels of competitiveness. This trend can be traced back to the practice of flexible manufacturing systems (Parthasarthy and Prakash, 1992; Bennet et al 1992). In order to achieve high levels of manufacturing agility, organisations must develop competencies in a number of different areas. Despite information systems being one of these factors, it is by no means the primary enabler. A number of other factors need to be considered and addressed to allow for the potential for information systems to contribute to higher levels of agility. This model of agility also suggests that an individual organisation cannot achieve high levels of agility by concentrating solely on its own operations and strategies. It proposes that a single organisation is dependent on the strategies and activities of its suppliers, and that the concept of supply chain management needs to be adopted in order to maximize the levels of agility that it can achieve.

Scholars have recognized that supply chains require more than a homogenous strategy for their successful operation. These strategies may vary according to the characteristics of the competitive environment in which they operate. Fisher (1997) suggests that supply chains can be categorized according to the nature of the supply chain (efficient or responsive) and the type of products that they produce (functional or innovative). Efficient supply chains are suited to functional products because this type of supply chain is suited to coping with predictable demand, and because of the products low margin is cheaper to operate. Conversely, responsive supply chains are suited to innovative products because they have the ability to respond to changes in demand and faster product life cycles. Due to the higher margin of these types of products, the increased revenues gained by being responsive compensates for the extra cost of operating this type of supply chain. Problems occur when there is a mismatch between the type of supply chain and type of product. Costs are incurred or revenue lost through carrying too much inventory or a failure to have stock in the right position in the supply chain to meet customers' needs. Christopher (2000) develops these themes with the introduction of lean and agile supply chains. Lean supply chains are defined as where volume is high and the variety and variability of the demand, for a product, is low. Agile supply chains however have high levels of variety and variability, and lower volumes. The five dimensions of an agile supply chain, as defined by van Hoek et al (2001), are described as customer sensitivity, virtual integration, process integration, network integration and measurement.

The concept of the lean/agile supply chains proposed by Christopher (2000) posits that they may not always have predictable or unpredictable demand all of the time. Therefore, supply chains may need to be lean for some of the time, and agile for the rest. This is similar to Zhang and Sharifi's (2000) concept of "agility need." Not all organisations possess the same level of need for the capability to be agile. This "agility need" level is determined by the level of change in the business environment, the characteristics of the environment and characteristics of the organisation. This is complemented by the "agility audit" developed by van Hoek et al (2001), which sought to measure the level of supply chain agility that an organisation possessed.

From an operational perspective, agile supply chains have been characterized as: utilizing virtual teams (Bal et al, 1999); having time compressed business processes (Mason-Jones and Towill, 1999); communicating real-time market data, via information systems, to all parties in the supply chain (Christopher and Towill, 
2001); making use of contract manufacturers (Mason et al, 2002); facilitating high levels of speed of change for throughput, destinations and volumes (Prater et al, 2001; Huang et al, 2002); utilising an inventory policy in seeking to dampen the effects of market related variance, through the creation of slack resources and appropriate order management activities (Caridi and Cigolini, 2002); and use of "de-coupling" and "postponement" points (Mason-Jones et al, 2000; van Hoek, 2000). Adapting supply chain with its individual strategies is critical in facing competition and depends on product behavior (e.g. product portfolio commoditization versus high product turnover rate) and product portfolio decisions (Seifert and Langenberg, 2011).

\section{Evolution of Supply Chain Technologies}

The important roles that information systems and technology play in supply chain management have repeatedly been highlighted in the literature (Ballou, 2007). These roles, among others, include improving supply chain efficiency (Alkadi et al., 2003), aligning business and supply chain strategies (Williams et al., 1997), increasing overall growth and profitability (Byrd and Davidson, 2003) and enabling supply chain agility (White et al., 2005; White and Mohdzain, 2009). Even the perception about trading partners' technology adoption, according to previous research, could improve the supply chain relationship between both parties (Kent and Mentzer, 2003).

Many different information systems can be included in the various categories of supply chain processes or functions. For example, planning systems may include material requisition planning (MRP), enterprise resource planning (ERP), capacity planning, production scheduling, sales planning, demand planning, transportation planning and shipment scheduling, which are all interrelated with other supply chain processes. There are also many different technologies used in these various areas of supply chain, such as bar code, electronic data interchange (EDI), quick response, cross-docking,

Radio-frequency
Identification (RFID), web services as well as different management approaches, such as vendor-managed inventory (VMI), customer relationship management (CRM), Kanban and Just-in-Time (JIT). Effectiveness of these systems and approaches, individually and collectively, improves the level of customer services and, in turn, the level of performance as indicated by customer loyalty, customer referrals and financial performance (Tracey, 1998).

Information systems and technology plays strategic roles particularly in facilitating the integration between different systems as well as enabling collaboration with trading partners (Williams, et al., 1997; Kumar and van Dissel, 1996). Supply chain collaboration has been defined as an attempt to achieve integrative settlements between transacting parties through integrations of behavioural, communicational and interactive flows (Morash and Clinton, 1998). Computer Science Corporation (CSC), in their survey, noted that there has been a steady increase in the amount of inter-organisational transactions done electronically, and that "connecting to customers, suppliers, and/or partners electronically" is one of the top ranked global management issues (CSC, 2001). More recent research shows that inter-organisational visibility, which is influenced by the supply chain partner's internal IS integration and interorganisational IT infrastructure compatibility, could predict supply chain performance (Kyu et al, 2011).

From IS/IT standpoint, supply chain collaboration refers to the linkages between different systems that enable transacting parties to perform interorganisational processes seamlessly. As shown in the framework developed by Kumar and van Dissel (1996), IS/IT plays the roles as both supporter and enabler to this collaboration. IS/IT collaboration is often achieved through the use of systems such as Vendor Managed Inventory (VMI), Supplier Management Systems (SMS) and Customer Relationship Management (CRM). In many cases, the development 
and maintenance of these systems are outsourced to IT vendors.

Inter-organisational systems may be classified into different typologies such as: Operational Cooperation, Resource Pooling, Operational Coordination and Complementary Cooperation (Hong, 2002); Pooled Information Resource, Value/Supply Chain and Networked (Kumar and van Dissel, 1996); and Hierarchical, Solar, Centreless and Swingle (Williams, 1997). Another framework developed by McLaren et al. (2002), characterized the degree of interorganisational integration (e.g. tight versus loose) and type of relationship (many-tomany, one-to-many, one-to-one). For instance, "offline trade exchanges" is used in many-to-many relationships where integration is loose, "shared collaborative systems" in one-to-one relationships where integration is tight, while telephone, facsimile and email in one-to-one relationships where integration is loose.

\section{Discussions and Research Framework}

Research studies into co-evolution have, for example, examined the co-evolution of strategy between different organisations within a given alliance (Koza and Lewin, 1999) or between IT and business domains within an organisation (Orlikowski, 1992). Also, previous studies have examined the different types of supply chain relationship, structure and strategies in relation to the use of inter-organisational systems (Kumar and van Dissel, 1996; Choudhury, 1997; Bensaou and Venkatraman, 1995). For example, Malhotra et al., (2005) developed and validated five types of IOS relationships: collector, connector, cruncher, coercer and collaborator. What remains unknown is how these different types of supply chain relationship facilitate or impede a coherent co-evolution between supply chain strategy and technology.
Co-evolution of supply chain strategy and technology requires a continuous collaboration between different entities within a given supply network. Such collaboration is exemplified by emergent concepts and technologies such as webbased Supplier Portal, Vendor-Managed Inventory and Web-EDI that help organisations to achieve agility in their supply chain network. These systems help increase visibility of information within transacting partners and require a high level of trust between these partners. Since most inter-organisational systems are developed by IT vendors, the concepts of visibility and trust must be understood by these vendors and translated into the systems they develop.

The proposed research framework focuses on the interactions between (1) institutional properties of IT vendors and adopting organisations (e.g. business model and strategy), (2) human agents of IT vendors and adopting organisations, and (3) supply chain technologies. While such interactions can relatively easily be conceptualised in a single organisation, in a supply chain collaboration where different organisations have different facilities - e.g. hardware and software, norms - e.g. protocols and etiquette, and interpretive schemes - e.g. assumptions and knowledge, these interactions tend to be more complex. Other than these internal factors, institutional influences on IT-collaboration also include mimetic pressures - to be more like other organisations, coercive pressures - pressures from other organisations, and normative pressures sharing norms with other organisations (Teo et al, 2003). 


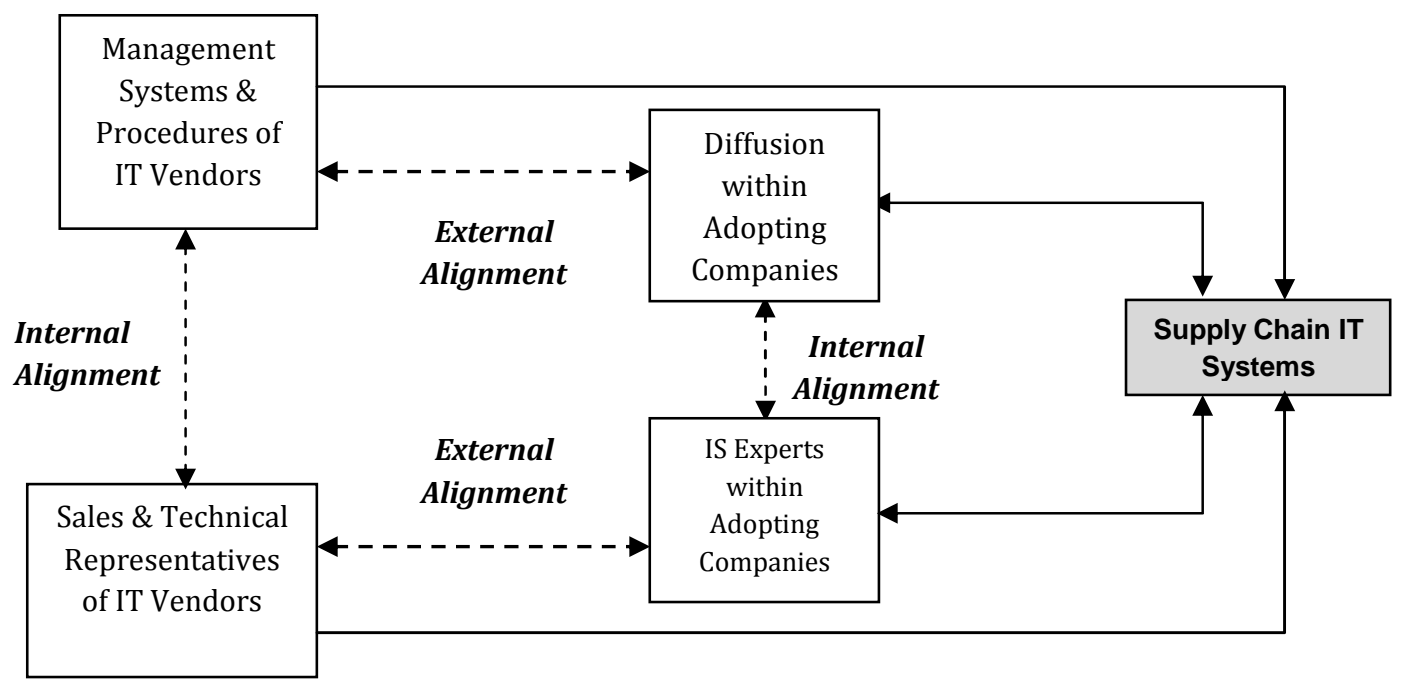

Fig 1. Research Framework

According to $\mathrm{He}$ et al (2011), "trust, commitment, interdependence, shared meaning, and balanced power facilitate knowledge transfer in supply-chain partnerships, and that knowledge transfer should be treated as a dynamic multistage process". Without effective mechanisms to facilitate the communication between the IT vendors and adopting organisations, systems designers use their own assumptions about user requirements, processes and strategies which may not be consistent with the supply chain strategy of the adopting organisation. As argued by Akrich (1992, p.208), "Designers thus define actors with specific tastes, competences, motives, aspirations, political prejudices, and the rest, and they assume that morality, technology, science, and economy will evolve in particular ways. A large part of the work of innovators is that of "inscribing" this vision of (or prediction about) the world in the technical content of the new object". Hence, there needs to be an effective mechanism to ensure that the development of supply chain information systems and technologies takes into account institutional properties of both the IT vendor and adopting organisations, that the impact of technology in facilitating and constraining the adopting organisations is well communicated to the IT vendors, and that knowledge is well spanned across organisational boundaries (Levina and Vaast, 2005). This activity is complicated by the fact that one IT vendor will serve multiple adopting organisations with different institutional properties. The reverse of this is also the case, with multiple IT vendors serving a single organisation. Furthermore, with the increased outsourcing of IT to third parties such as CSC, EDS and Accenture, complexity is increased substantially due to their mediating role in the relationship between IT vendors and adopting organisations. Such communication is represented by the dotted lines.

The proposed framework emphasizes on the internal fit and alignment between supply chain and IT in both; the vendor and adopting companies as well as external fit and alignment between vendor and adopting companies in both supply chain and IT. An effective communication and coordination mechanisms would enable better alignment that potentially results in effective transfer of knowledge between different parties involved. These mechanisms are depicted in Figure2 below. 


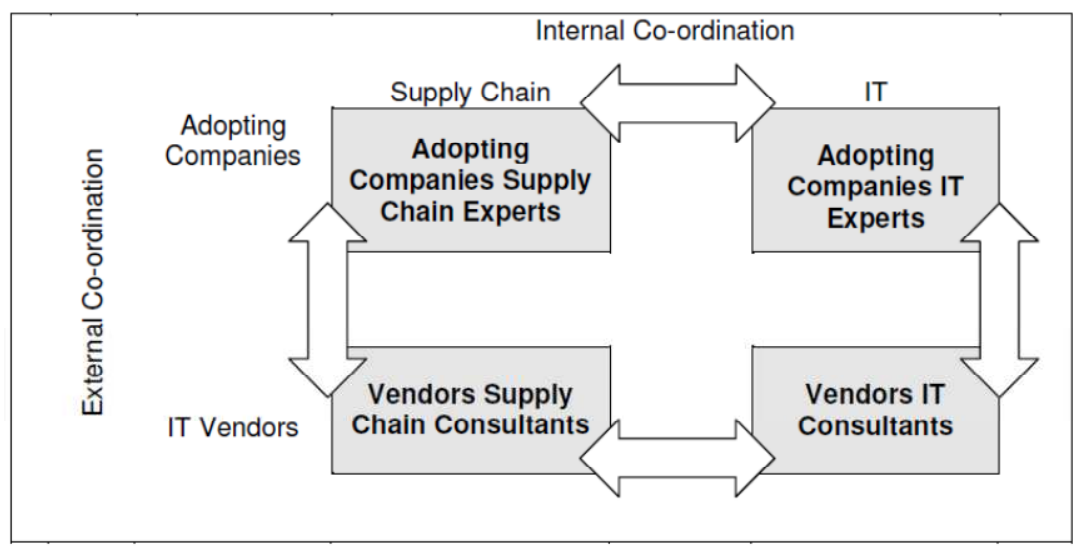

Fig.2: Co-Ordination Mechanisms

\section{Conclusions}

In the supply chain strategy, the focal shift in strategy has been from lean to agile, whereas in supply chain, it is technology from individual to inter-organisational systems. Examples of these systems include Vendor-Managed Inventory and use of Web-Electronic Data Interchange. These systems increase visibility of information within the supply network and require a high level of trust between the trading partners. Since most interorganisational systems are developed by IT vendors, the concepts of visibility and trust must be understood by these vendors and translated into the systems they develop. Lack of such understanding would result in technology overtaking management's capabilities to capture the full benefits of systems to be developed (Koh et al, 2011). The proposed framework emphasizes the focus on fit and alignment between progress in supply chain strategies and IT strategies that would potentially enable agility as well as trust and visibility within the supply network.

\section{References}

Akrich, M. (1992)."The Description of Technical Objects," In W. E. Bijker, J. Law, eds. Shaping Technology/Building Society: Studies in Sociotechnical Change. MIT Press: Cambridge, MA. 205-224.
Alkadi, I., Alkadi, G. \& Totaro, M. (2003)."Effects of Information Technology on the Business World," Human Systems Management, 22(3). 99-103.

Bal, J., Wilding, R. \& Gundry, J. (1999)."Virtual Teaming in the agile Supply Chain," International Journal of Logistics Management, 10(2). 71-82.

Ballou, R. H. (2007)."The Evolution and Future of Logistics and Supply Chain Management," European Business Review, 19(4). 332-348.

Bennett, D., Forrester, P. \& Hassard, J. (1992)."Market-Driven Strategies and the Design of Flexible Production Systems: Evidence from the Electronics Industry," International Journal of Operations \& Production Management, 12(2). 25-38.

Bensaou, M. \& Venkatraman, N. (1995)."Configurations of Interorganizational Relationships: a Comparison between U.S. and Japanese Automakers," Management Science, 41 (9). 1471-1492.

Byrd, T. A. \& Davidson, N. W. (2003)."Examining Possible Antecedents of IT Impact On the Supply Chain and Its Effect on Firm Performance," Information and Management, 41(2). 243-255. 
Caridi, M. \& Cigolini, R. (2002)."Improving Materials Management Effectiveness: a Step towards the Agile Enterprise," International Journal of Physical Distribution and Logistics Management, 32(7). 556-576.

Choudhury, V. (1997)."Strategic Choices in the Development of Interorganizational Information Systems," Information Systems Research, 8 (1). 1-24.

Christopher, M. (2000)."The Agile Supply Chain," Industrial Marketing Management, 29(1). 37-44.

Christopher, M. \& Towill, D. (2001)."An Integrated Model for the Design of Agile Supply Chains," International Journal of Physical Distribution and Logistics Management, 31(4). 235-246.

Cooper, M. C. \& Ellram, L. M. (1993)."Characteristics of Supply Chain Management and the Implication for Purchasing and logistics Strategy," The International Journal of Logistics Management, 4(2). 13-24.

CSC (2001).'Critical Issues of Information Systems Management - 14th Annual Survey of I/S Management Issues,' Computer Science Corporation (CSC). USA: El Segundo, California.

Fisher, M. L. (1997)."What is the Right Supply Chain for your Product?," Harvard Business Review, 75(2). 105-116.

Garcla-Dastugue, S. J. \& Lambert, D. M. (2003)."Internet-Enabled Coordination in the Supply Chain," Industrial Marketing Management, 32(3). 251-263.

He, Q., Gallear, D. \& Ghobadian, A. (2011)."Knowledge Transfer: The Facilitating Attributes in Supply-Chain Partnerships," Information Systems Management, 28(1). 57-70.

Hong, I. B. (2002)."A New Framework for Interorganizational Systems Based on The Linkage of Participants' Roles," Information and Management, 39(4). 261-270.
Huang, S. H., Uppal, M. \& Shi, J. (2002)."A Product Driven Approach to Manufacturing Selection," Supply Chain Management, 7(3/4). 189-199.

Kent, J. L. \& Mentzer, J. T. (2003)."The Effect of Investment in Interorganizational Information Technology in a Retail Supply Chain," Journal of Business Logistics, 24(2). 155-175.

Kim, K. K., Ryoo, S. Y. \& Jung, M. D. (2011)."Inter-organizational Information Systems Visibility in Buyer-Supplier Relationships: the Case of Telecommunication Equipment Component Manufacturing Industry," Omega, 39(6). 667-676.

Koh S. C. L., Gunasekaran A., Goodman T. (2011)."Drivers, Barriers and critical Success Factors for ERPII Implementation in Supply Chains: a Critical Analysis," Journal of Strategic Information Systems, Article in Press.

Koza, M. P. \& Lewin, A. Y. (1999)."The Coevolution of Network Alliances: A Longitudinal Analysis of an International Professional Service Network," Organization Science, 10(5). 638-653.

Kumar, K. \& van Dissel, H. G. (1996)."Sustainable Collaboration: Managing Conflict and Cooperation in Interorganizational Systems," $\quad$ MIS Quarterly, 20(3). 279-300.

Lambert, D. M., Cooper, M. C. \& Pagh, J. D. (1998)."Supply Chain Management: Implementation Issues and Research Opportunities," International Journal of Logistics Management, 9(2). 1-19.

Levina, N. \& Vaast, E. (2005)."The Emergence of Boundary Spanning Competence In Practice: Implications For Implementation And Use Of Information Systems". MIS Quarterly, 29(2). 335-363.

Malhotra, A., Gosain, S. \& El Sawy, 0. A. (2005)."Absorptive Capacity Configurations in Supply Chains: Gearing for Partner-Enabled Market Knowledge Creation," MIS Quarterly, 29(1). 145-187. 
Mason-Jones, R., Naylor, B. \& Towill, D. R. (2000)."Engineering the Leagile Supply Chain," International Journal of Agile Management Systems, 2(2). 54-61.

Mason-Jones, R. \& Towill, D. R. (1999)."Total Cycle Time Compression and the Agile Supply Chain," International Journal of Production Economics, 62(1/2). 61-73.

Mason, S. J., Cole, M. H., Ulrey, B. T. \& Yan, L. (2002)."Improving Electronics Manufacturing Supply Chain Agility through Outsourcing," International Journal of Physical Distribution and Logistics Management, 32(7). 610-620.

McLaren, T. Head, M. \& Yuan, Y. (2002). Supply Chain Collaboration Alternatives: Understanding The Expected Costs And Benefits, Internet Research, 12(4). 348-365

Mentzer, J. T., DeWitt, W., Keebler, J. S., Min, S., Nix, N., Smith, C. D. \& Zacharia, Z. G. (2001)."Defining Supply Chain Management," Journal of Business Logistics, 22(2). 1-25.

Morash, E. A. (2001)."Supply Chain Strategies, Capabilities and Performance," Transportation Journal, 41(1). 37-54.

Morash, E. A. \& Clinton, S. R. (1998)."Supply Chain Integration: Customer Value through Collaborative Closeness versus Operational Excellence," Journal of Marketing Theory \& Practice, 6(4). 104-120.

Orlikowski, W. J. (1992)."The Duality of Technology: Rethinking the Concept of Technology on Organizations," Organization Science, 3(3). 398-427.

Parthasarthy, R. \& Prakash, S. (1992)."The Impact of Flexible Automation on Business Strategy and Organizational Structure," The Academy of Management Review, 17(1). 86112.

Prater, E., Biehl, M. \& Smith, M. A. (2001)."International supply chain agilityTradeoffs between flexibility and uncertainty," International Journal of Production and Operations Management, 21(5/6). 823-839.
Schonsleben, P. (2000)."with Agility and Adequate Partnerships Strategies towards Effective Logistics Networks," Computers in Industry, 42(1). 33-42.

Seifert R. W. \& Langenberg K. U. (2011)."Managing Business Dynamics with Adaptive Supply Chain Portfolios," European Journal of Operational Research, 215(3). 551-562.

Teo, H. H., Wei, K. K. \& Benbasat, I. (2003)."Predicting Intention To Adopt Interorganizational Linkages: An Institutional Perspective," MIS Quarterly, 27(1). 19-49.

Tracey, M. (1998)."The Importance of Logistics Efficiency to Customer Service and Firm Performance," International Journal of Logistics Management, 9(2). 6581.

Van Hoek, R. I. (2000)."The Thesis of Leagility Revisited," International Journal of Agile Management Systems, 2(2). 196-201.

Van Hoek, R. I., Harrison, A. \& Christopher, M. (2001)."Measuring Agile Capabilities in the Supply Chain," International Journal of Production and Operations Management, 21(1/2). 126-147.

White, A., Daniel, E. M., \& Mohdzain, M. (2005)."The Role of Emergent Information Technologies and Systems in Enabling Supply Chain Agility," International Journal of Information Management, 25(5). 396410.

White, A. D. \& Mohdzain, M. B. (2009)."An Innovative Model of Supply Chain Management: A Single Case Study in the Electronics Sector," International Journal of Information Technology and Management, 8(1). 69-84.

Williams, L. R., Nibbs, A., Irby, D. \& Finley, T. (1997)."Logistics integration: the Impact of Information Technology, Team Composition, and Corporate Competitive Positioning," Journal of Business Logistics, 18(2). 31-41.

Williams, T. (1997)."Interorganizational Information Systems: Issues Affecting 
9 Journal of Enterprise Resource Planning Studies

Interorganizational Cooperation," Journal of Strategic Information Systems, 6(3). 231250.

Zhang, Z. \& Sharifi, H., (2000)."A Methodology For Achieving Agility in Manufacturing Organisations," International Journal of Operations \& Production Management, 20(4). 496-513. 